REVISTA DE GESTAOO SEECRETRRADO

MANAGEMENT AND ADMINISTRATIVE PROFESSIONAL REVIEW
Organização: SINSESP

Editora Científica: Dra. Cibele B. Martins

Avaliação: Double Blind Review pelo SEER/OJS

Revisão: Gramatical, normativa e de formatação

Data de recebimento do artigo: 29-12-2017

Data de aceite do artigo: $8-3-2018$

DOI: http://dx.doi.org/10.7769/gesec.v9i1.771

\title{
A regra do jogo: relação entre Estado e Terceiro Setor
}

\author{
Amanda Florense Alves Amorim \\ Mestre em Administração pela Universidade Federal da Paraíba (UFPB). \\ E-mail: amanda ipnv@hotmail.com (Brasil). \\ Josiete da Silva Mendes \\ Mestra em Administração pela Universidade Federal da Paraíba (UFPB). \\ E-mail: josiete5@hotmail.com (Brasil). \\ Layse Maria Leite Pereira \\ Mestranda em Administração na Universidade Federal da Paraíba (UFPB). \\ E-mail: layseleite@hotmail.com (Brasil).
}

\section{Carlos Eduardo Cavalcante}

Doutor e Mestre em Administração pela Universidade Federal do Rio Grande do Norte (UFRN).

Professor Adjunto da Universidade Federal da Paraíba (UFPB).

E-mail: cavalcanteeduardo@gmail.com (Brasil).

\section{RESUMO}

Este estudo analisa as relações interorganizacionais entre o Estado (Governo do Estado da Paraíba) e organizações não governamentais dos direitos das mulheres. Trata-se de um estudo de campo, qualitativo, descritivo usando um roteiro semiestruturado e análise de conteúdo categórico. As categorias de análise são: rede de valor de ONG e o modelo de PARTS (jogadores, valores adicionais, regras, táticas e escopo). Também foi avaliada a influência da criação da Secretaria de Estado das Mulheres e da Diversidade Humana. Pode-se deduzir que as alianças intersetoriais (parcerias) proporcionam o fortalecimento da relação entre ONGs e Estado. Também pode haver uma relação de coopetição - termo herdado da base teórica utilizada - entre as organizações, e este cenário tende a manter a convergência de interesses.

PALAVRAS-CHAVE: Coopetição. Poder. Terceiro Setor. Estado. ONG. 


\title{
Game Rules: State and Third Sector Relationships
}

\begin{abstract}
This study analyzes the interorganizational relationships between State (Paraíba State Government) and women's rights non-governmental organizations. This is a qualitative, descriptive and field research, using a semi-structured script and narrative and categorical content analysis. The categories of analysis are: NGO value network and the PARTS model (players, additional values, rules, tactics and scope). In addition, influence of the Secretariat State creation for Women and Human Diversity was evaluated. It can be inferred that intersector alliances (partnerships) provide the strengthening of the relationship between NGOs and State. There may also be a relationship of coopetition - term from theoretical basis used - between organizations, and this scenario tends to maintain the convergence of interests.
\end{abstract}

KEYWORDS: Coopetition. Power. Third Sector. State. NGO.

\section{Como referenciar em APA:}

Amorim, A. F. A., Mendes, J. S., Pereira, L. M. L., \& Cavalcante, C. E. (2018). A regra do jogo: relação entre Estado e Terceiro Setor. R.G.Secr.,GESEC, 9(1). doi: http://dx.doi.org/10.7769/gesec.v9i1.771

\section{Como referenciar em ABNT:}

AMORIM, A. F. A.; MENDES, J. S.; PEREIRA, L. M. L.; CAVALCANTE, C. E. A regra do jogo: relação entre Estado e Terceiro Setor. R.G.Secr.,GESEC, v. 9, n. 1, 2018. doi: http://dx.doi.org/10.7769/gesec.v9i1.771
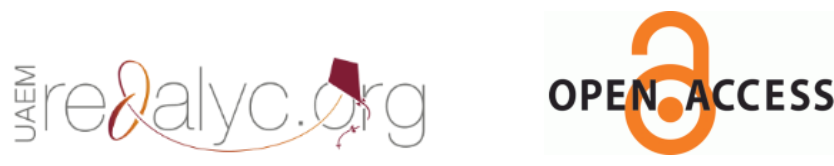


\section{Introdução}

Desde o final da década de 1970, as transformações econômicas, políticas e sociais têm intensificado relações entre organizações e dando origem a redes complexas que necessitam de alianças interorganizacionais para o fluxo de informações, capital, influência, mercadorias e serviços (Eiriz, 2001; Weymer \& Machado-da-Silva, 2006).

Nesse contexto, Austin (2001) afirma que alianças estabelecidas com propósitos estratégicos entre organizações são uma realidade independentemente do setor: Estado, Mercado ou Terceiro Setor. Porém, entre tais alianças, pode-se dizer que as organizações do terceiro setor atuam na faixa difusa entre o setor público e o privado.

Partindo de discussões que envolvem Terceiro Setor e Estado, é relevante destacar que há posicionamentos divergentes quanto a essa relação, que podem ser de cooperação ou competição. A Teoria dos Bens Públicos (Weisbrod, 1977) e a Teoria da Interdependência (Salamon \& Anheier, 1998) esclarecem essas relações aparentemente divergentes.

A Teoria dos Bens Públicos defende o surgimento do terceiro setor como uma resposta à falha do Mercado e Estado em satisfazer as necessidades da sociedade, por isso esses setores pertenceriam a lados opostos e rivais (Anheier, 2005; Salamon \& Anheier, 1998; Weisbrod, 1977). A Teoria da Interdependência, por sua vez, defende a origem do terceiro setor como meio de complementar as ações do Estado, que financia seus serviços, estabelecendo assim uma relação cooperativa (Salamon \& Anheier, 1998).

$\mathrm{Na}$ área de estudos de terceiro setor convivem dois grupos de defensores: há aqueles que defendem a cooperação e os que defendem a competição. Por exemplo, Calegare, Silva Júnior (2009) e Rifkin (1997), afirmam que a responsabilidade cívica em atender uma demanda reprimida passa a ser das organizações do Terceiro Setor devido à redução do papel do Estado, colocando-os em polos rivais. Em contrapartida, Coelho (2000) observa essa relação como complementadora, afirmando a possibilidade e necessidade desses setores estabelecerem parceria e colaboração, assim como argumenta a Teoria da Interdependência (Salamon \& Anheier, 1998).

Entretanto, há a possibilidade de uma terceira via denominada de "coopetição". Para Nalebuff e Brandenburger (1996), coopetição é uma relação híbrida e simultânea entre competição e cooperação. Para Dagnino e Padula (2002) trata-se de uma forma que conceitua a dinâmica de interdependência entre empresas, em que há uma estrutura de convergência parcial de interesses e objetivos entre os envolvidos. É uma estrutura de jogos de ganho 
positivo, com variações, tendo em vista que existem incertezas oriundas da pressão competitiva.

Observa-se a ligação que a abordagem da coopetição estabelece com a Teoria dos Jogos, utilizando-a inclusive como base conceitual (Souza, 2003). Nesse sentido, tal teoria parte da premissa de equacionar, por meio do raciocínio lógico, os conflitos de interesse que ocorrem frequentemente na sociedade, verificando tendências entre jogadores de maximizar o ganho individual (Motta \& Vasconcelos, 2006; Souza, 2003).

Assim, considerando o contexto específico deste artigo tem-se que na relação entre ONG (terceiro setor) e Estado (primeiro setor) deve-se considerar dois importantes fatos: o governo tem o poder de criar várias regras do jogo por meio de leis, decretos e regulamentos; e o terceiro setor tem o poder de mobilização das causas e demandas sociais, que são ou deveriam ser impulsionadoras de ações governamentais. Logo, parte-se do princípio que "esse tipo de parceria comporta uma complexidade inelutável, pois ele dá lugar a arranjos sociais marcados pela confrontação entre duas lógicas de ação bem diferentes" (Serva, 1997, p. 45).

Além do destaque conceitual de Serva, algumas pesquisas empíricas tratam dessa relação que ora é de cooperação, ora de competição. Fischer (2005) constatou dificuldades no gerenciamento de alianças intersetoriais, tais como: desequilíbrio de poder entre organizações aliadas; falta de conhecimento mútuo das expectativas e indefinição prévia dos resultados esperados; problemas das diferenças entre culturas organizacionais; inexistência de indicadores de avaliação; e monitoramento. Na pesquisa de Sucupira, Chaves e Monteiro (2007) com nove dirigentes de ONG, foi verificada insatisfação por parte dos entrevistados na relação com o Estado, devido às dificuldades inerentes a essas alianças. Ainda, eles mostraram considerar o processo de aproximação importante para o aprofundamento da democracia.

Historicamente, a partir da década de 1970, iniciou-se uma relação de confronto entre sociedade civil organizada e Estado, ampliada em 1980 quando predominou a postura de reivindicação, e por volta de 1990, quando construiu-se ambiente favorável à aproximação de diferentes organizações (Bresser-Pereira \& Grau, 1999; Sucupira et. al., 2007).

Nesse sentido, pode-se dizer que após um período de embate entre os dois setores, seguiu-se uma aproximação, levando as ONGs a empreender diferentes relações com o poder público. Como consequência, as instituições passaram a conviver com o dilema entre constituírem-se como agentes do aprofundamento da democracia, dado o seu histórico compromisso político com movimentos sociais, ou tornarem-se, em virtude de sua 
profissionalização e capacidade técnica, substitutas do papel do Estado no fornecimento de serviços públicos à população (Dagnino \& Padula, 2002; Jaime, 2005; Oliveira, 2002; Teixeira, 2003).

Nota-se, portanto, uma espécie de pêndulo na relação entre esses dois entes: ora se aproximam, compartilhando interesses; ora se afastam, assumindo posições opostas. Um setor em especial, o de defesa dos direitos da mulher, parece estar no momento de aproximação, compartilhando aparentemente interesses com o Estado, relação que começou há alguns anos.

Na década de 1990 eclodiram movimentos sociais organizados, entre eles o de defesa dos direitos da mulher. Essas organizações são oriundas de um processo histórico de lutas por políticas públicas que promovem a equidade de gênero por meio do enfrentamento à discriminação de todas as formas preconceituosas inerentes às disparidades entre o "papel feminino" em relação ao "masculino".

Além de lutas comuns ao movimento feminista, no que tange às desigualdades sexuais e violência doméstica, uma das pautas do movimento na Paraíba foi a da criação de um mecanismo na estrutura governamental que acolhesse as demandas de políticas públicas para resolução das reivindicações. Em 2008, foi instalado o debate para a criação da Secretaria da Mulher e a reestruturação do Conselho Estadual dos Direitos da Mulher (Secretaria de Estado da Mulher e da Diversidade Humana, [n.d.]).

Em 2009 esse objetivo foi alcançado pela criação do programa estadual de políticas públicas para mulheres da Paraíba, vinculado à casa civil do governador, por meio do Decreto n. 30.391. Em março de 2010 a Secretaria Especial de Estado de Políticas Públicas para Mulheres da Paraíba foi criada por meio da Medida Provisória n. 149, transformada posteriormente em lei com o Decreto n. 9.077/2010 (Secretaria de Estado da Mulher e da Diversidade Humana, [n.d.]; Vieira, 2014).

$\mathrm{Na}$ atualidade, o governo da Paraíba alterou o decreto de criação dessa secretaria, por meio da Lei n. 10.467, de 26 de maio de 2015, e recentemente pela Lei n. 10.569, de 19 de novembro de 2015, criando a Secretaria de Estado da Mulher e da Diversidade Humana (SEMDH), que contempla além da pauta de luta pelos direitos das mulheres, as causas LGBT (Lésbicas, Gays, Bissexuais e Transexuais), de ciganos, índios, entre outros grupos que se incluam no aspecto de diversidade e minorias.

O que se percebe é que, a partir dessas informações, há tendência de convergência de interesses entre organizações de defesa de direitos de mulheres e Estado. Entretanto deve ser destacado que esse contexto foi permeado por forte presença de recursos financeiros; esse 
cenário mudou, porém, com a saída da presidente Dilma Rousseff, pois o Governo Federal passa por fortes contingenciamentos em todos os ministérios, com cortes em torno de $45 \%$ neste ano.

Assim, interessa aos autores deste estudo saber se, com a mudança de postura de apoiador dessas organizações, mantém-se a tendência de convergência de interesses. Então, diante do contexto descrito, este trabalho tem como objetivo analisar as relações interorganizacionais entre Estado e ONG a partir da ótica das dirigentes das instituições Cunhã Coletivo Feminista e Centro da Mulher 8 de Março (CM8M), e o Governo do Estado da Paraíba, tendo como perspectiva teóricas os estudos de Nalebuff e Brandenburger (1996) e como marco cronológico a criação da Secretaria Especial de Estado de Políticas Públicas para Mulheres da Paraíba.

O estudo em questão selecionou dentre o amplo campo do terceiro setor essas duas ONGs por serem as mais antigas da cidade de João Pessoa na luta pelos direitos das mulheres. Assim, acredita-se que esta análise vem somar esforços por subsidiar gestores de forma prática na avaliação do impacto de medidas como essa nas relações intersetoriais.

Para ter acesso a essas organizações, utilizou-se o mapeamento realizado pelo grupo de pesquisa do qual fazem parte os autores (buscando manter o anonimato, apenas se o artigo for aceito o nome do grupo será informado) no qual constam 110 organizações do estado da Paraíba, e, após análise, escolheu-se a Cunhã Coletivo Feminista e o Centro da Mulher 8 de Março por serem pioneiras no Estado na luta dos direitos femininos. Outro fator motivador de escolha deu-se pelas observações das pesquisadoras de que as ONGs se organizam em rede, estabelecendo frequentes alianças com outras entidades e com organismos governamentais, sendo tal constatação importante para o confronto com a teoria utilizada neste estudo.

Para alcançar os objetivos propostos, este artigo está apresentado primeiramente uma análise teórica da temática abordada, em seguida será apresentada a metodologia que amparou a investigação da pesquisa, logo após serão apresentadas as análises dos resultados, e por fim, as principais considerações do estudo realizado, bem como sugestões para trabalhos futuros.

\section{Fundamentação Teórica}

\subsection{Cooperação + Competição: Coopetição}

De acordo com Weymer e Machado-da-Silva (2006), as organizações dificilmente 
sobrevivem isoladas em seu contexto, pois precisam manter relações interorganizacionais nas quais fluem informações, capital, influência, mercadorias e serviços. Portanto, as organizações que antes visualizavam a relação com a concorrência como uma verdadeira disputa, compreenderam que "há poucos vencedores quando os negócios são conduzidos como uma guerra" (Nalebuff \& Brandenburger, 1996, p. 13), fazendo assim emergir a necessidade de redes e alianças estratégicas.

Alianças estratégicas baseiam-se nas relações de colaboração entre organizações a partir da teoria da trissetorialidade, que define três classificações nas quais as instituições podem estar inseridas: primeiro setor (órgãos públicos); segundo setor (organizações com fins lucrativos) e terceiro setor (organizações da sociedade civil que se caracterizam pelas finalidades públicas com emprego de recursos privados) (Austin, 2001).

Nesse contexto, Dowbor (2002) afirma que relacionamentos sob a forma de parcerias tornam-se meio de busca de soluções sustentáveis para problemas do desenvolvimento social, uma vez que as dimensões da desorganização social existentes têm gerado gigantesco desperdício de recursos. Portanto, a partir das alianças intersetoriais torna-se possível a implementação de projetos que objetivam beneficiar uma comunidade, ou mesmo divulgar e defender uma causa de interesse público.

Segundo Cândido e Abreu (2000), organizações de maneira geral encontram-se em uma importante rede social, devendo ser analisadas como tal. Corroborando, Machado-daSilva e Coser (2006) afirmam que o conceito de rede demonstra uma noção abstrata que se refere a um conjunto de nós conectados por relacionamentos, de modo que redes interorganizacionais são importantes quanto à capacidade de regular interdependências transacionais mais complexas, gerando ainda o que se chama rede de valores.

A rede de valores, descrita por Nalebuff e Brandenburger (1996), compreende elementos, atividades e envolvidos principais em uma rede interorganizacional a partir da criação e das trocas de valores, no que tange às informações, conhecimento e bens tangíveis, conforme apresenta a Figura 1: 
Figura 1 - Rede de valores.

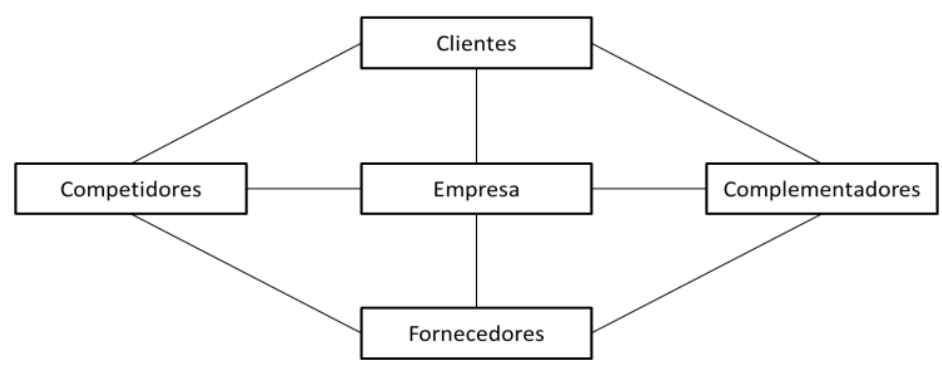

Fonte: Nalebuff e Brandenburger (1996, p. 29)

A rede de valores demonstrada na figura posiciona os jogadores existentes nas relações estabelecidas entre si. No entanto, faz-se necessário destacar que essa rede representa tão somente o papel que alguém desempenha, de modo que o mesmo jogador pode exercer múltiplas funções, não sendo viável, portanto, determinar alguém como apenas freguês, fornecedor, concorrente ou complementador, pois as regras alteram o equilíbrio de poder e podem ser usadas para reestruturar relações em benefício de determinados participantes nas negociações, entendendo assim, que se trata de uma rede dinâmica.

A partir da compreensão de que o estabelecimento de redes interorganizacionais e alianças estratégicas são vitais para o bom funcionamento das organizações, uma vez que não possuem em sua totalidade todos os recursos necessários para atuação das atividades, faz-se necessário destacar que existem diferentes tipos de relações em uma rede de valor, de modo que assim como Nalebuff e Brandenburger (1996) afirmam, cada organização possui a opção de adotar sua postura de atuação conduzida por meio de um jogo de interesses.

Tomando a competição como o primeiro dos relacionamentos em rede, Oliver (1990) ressalta que, em um ambiente de constantes mutações, fica evidente a necessidade de planejamento para a competição, uma vez que, em jogos, os conflitos são naturais. Complementarmente, Nalebuff e Brandenburger (1996) afirmam que a competição, em dadas circunstâncias, faz que os envolvidos não apenas se considerem concorrentes, mas também acreditem que seu sucesso depende do fracasso do outro sob a premissa de que se forem capazes de definir regras entre seus concorrentes, dada maior influência, será possível mudar o jogo da concorrência a seu favor.

Em outro extremo encontra-se a cooperação no relacionamento das redes, que por sua vez, busca regular as relações por meio da "paz" e parceria, entendendo que muitas empresas só serão bem-sucedidas se outras também forem (Nalebuff \& Brandenburger, 1996). Porém, 
compreendendo que nem tudo está relacionado à competição ou cooperação, surge um novo conceito por meio de Nalebuff e Brandenburger (1996), denominado "coopetição".

"Coopetição" é uma forma diferente de entender os negócios, tendo em vista que nas interações entre organizações muitas vezes ocorrem simultaneamente cooperação e competição (Eikebrokk \& Olsen, 2005), assim como os próprios autores Nalebuff e Brandenburger (1996) enfatizam, negócio é cooperação quando o objetivo é criar o bolo e concorrência quando chega a hora de dividi-lo, não se tratando de ciclos separados de competição seguidos de colaboração, mas de uma combinação que resulta em relacionamento dinâmico e híbrido que nos jogos organizacionais podem tornar múltiplos vencedores.

Nesse contexto, Azevedo, Carvalho e Silva (1999) indicam que, para adoção de um relacionamento a partir da coopetição, faz-se necessária a definição dos pontos fortes e fracos das organizações envolvidas mediante análise detalhada do presente para projeção futura. Nesse sentido, Nalebuff e Brandenburger (1996) discutem a abordagem da coopetição propondo como base os fundamentos da Teoria dos Jogos e relações de poder para a maximização da capacidade de uma organização gerar rede de valor que gere benefícios.

A partir do cenário estabelecido quanto à Teoria dos Jogos e as relações de poder, entre a perspectiva da coopetição de Nalebuff e Brandenburger (1996) identificam-se os cinco principais elementos do jogo: jogadores - pessoas que compõem as organizações; valores adicionais - que dimensionam a contribuição de cada jogador, sendo inclusive o elemento que determina quem tem mais níveis de poder no jogo; regras - que têm como função estruturar a maneira como o jogo é jogado, como as relações interorganizacionais realizam-se em decorrência de costumes, contratos ou até mesmo da lei; táticas - que compreendem as ações capazes de moldar e influenciar as percepções das outras pessoas envolvidas no jogo, de modo que com poder tático de alterar as percepções do outro quanto às situações e relações, tem-se a possibilidade de alterar as próprias jogadas; e por fim escopo - limites que implicitamente as pessoas atribuem ao jogo quando são definidos, entendendo que redes organizacionais não estão imersas em um jogo específico, mas em diversos outros simultaneamente em que cada um é interligado por elos invisíveis a outro, fazendo assim que ações em determinado momento sejam fruto de um jogo anterior ou gerem impactos em cenários futuros. 


\section{Metodologia}

Esta pesquisa caracterizou-se por ser uma abordagem qualitativa em profundidade, dedutiva, de campo e um estudo de caso múltiplo. Assim, os sujeitos selecionados para esta pesquisa foram as duas dirigentes das ONG "Cunhã Coletivo Feminista" e "Centro da Mulher 8 de Março", localizadas em João Pessoa (PB), as quais receberam o tratamento neste trabalho de "Dirigente A" para Cunhã Coletivo Feminista e "Dirigente B" para o CM8M.

Tal escolha foi motivada por serem responsáveis pelo canal de diálogo direto com o Estado, representando institucionalmente as entidades. Outro fator que contribuiu é que, ao entrarem em contato com as ONGs, as pesquisadoras foram direcionadas a tratar do assunto com as dirigentes, dado o grau de profundidade das questões pela abordagem qualitativa.

$\mathrm{O}$ instrumento de coleta de dados foi um roteiro de entrevista semiestruturada gerado a partir da perspectiva de coopetição proposta por Nalebuff e Brandenburger (1996), a qual foi subdividida estruturalmente em três partes: informações gerais sobre a ONG; identificação da rede de valores e das PARTS - jogadores; valores adicionais; regras; táticas; e escopo. A seguir, apresenta-se o Quadro 1 com as categorias de análises e elementos analisados no estudo.

Quadro 1 - Categorias de análise e elementos analisados na pesquisa.

\begin{tabular}{|l|l|}
\hline CATEGORIAS & ELEMENTOS ANALISADOS \\
\hline Rede de valor & $\begin{array}{l}\text { - Relação das ONG com o Estado. } \\
\text { - Impacto dessa relação para o público-alvo. } \\
\text { - Equilíbrio do poder de decisão mediante a relação com o Estado. }\end{array}$ \\
\hline Jogadores & $\begin{array}{l}\text { - Quem são os jogadores da rede de valores? } \\
\text { - Existem indivíduos das ONGs que trabalham no Estado? }\end{array}$ \\
\hline Valores adicionais & $\begin{array}{l}\text { - Quais as contribuições das ONGs para seu contexto? } \\
\text { - Essas contribuiços são únicas ou outros podem desempenhar? }\end{array}$ \\
\hline Regras & Possíveis valores adicionais copiados por outras entidades. \\
\hline Táticas & $\begin{array}{l}\text { - Regras mantidas na relação das ONGs com o Estado. } \\
\text { - Procedimentos formais dessa relação. }\end{array}$ \\
\hline Escopo & $\begin{array}{l}\text { - Capacidade das ONGs influenciarem o ambiente. } \\
\text { - Percepções que as ONGs gostariam de preservar entre si e o Estado. } \\
\text { - O que as ONGs mudariam em suas relações com o Estado? }\end{array}$ \\
\hline Criação da SEMDH & - Limites na relação das ONGs e Estado. \\
\hline
\end{tabular}

Fonte: Elaboração própria (2017)

As entrevistas duraram cerca de 40 minutos na sede das organizações em agosto de 
2016, segundo a disponibilidade das dirigentes. Inicialmente, as entrevistadas foram introduzidas a uma apresentação oral do objetivo da pesquisa, perguntou-se se as falas poderiam ser gravadas, as dirigentes concordaram e posteriormente as perguntas da entrevista seguiram o roteiro proposto.

Para tanto foi utilizada a análise de narrativas como estratégia mais adequada para avaliação de dados, partindo do pressuposto de que a realidade é socialmente construída por meio das interações sociais das pessoas, de modo que as organizações e suas estratégias são vistas também como socialmente construídas, legítimas e institucionalizadas a partir de interações e práticas sociais (Berger \& Luckmann, 2003; Geertz, 1989).

A interpretação de dados ocorreu por meio de análise de conteúdo das narrativas a partir das categorias relacionadas no Quadro 1 e a respectiva análise das falas das dirigentes entrevistadas. Ao término das etapas, busca-se alcançar o objetivo central do trabalho e, portanto, segue nesta próxima seção a análise dos dados obtidos.

\section{Resultados e Discussões}

A seguir, apresenta-se a rede de valores, durante as entrevistas foi possível perceber com maior predominância a relação ONG-Estado, desse modo a variável é colocada neste estudo objetivando uma análise do contexto externo que as entidades em questão estão inseridas. Em seguida é realizada a análise das variáveis do modelo das PARTS (Nalebuff \& Brandenburger, 1996). Por fim, analisa-se a influência da criação da SEMDH na relação ONG-Estado, que apesar de não estar prevista no roteiro, considerou-se importante destacá-la nos resultados, depois da análise das falas das dirigentes.

\subsection{Identificando a rede de valores}

Segundo Nalebuff e Brandenburger (1996), esboçar a rede de valores é um valioso exercício, pois é a partir dela que se torna possível compreender perspectivas do público-alvo e dos fornecedores. Assim, não ter uma rede definida torna-se problema, pois quando não se sabe explicitamente quem são os jogadores, as organizações acabam por desconsiderar alguns aspectos importantes inerentes ao jogo. 
Quadro 2: Rede de valores das ONGs.

\begin{tabular}{|l|l|}
\hline Cunhã Coletivo Feminista & Centro da Mulher 8 de Março \\
\hline Público-alvo: mulheres, de maneira geral & $\begin{array}{l}\text { Público-alvo: mulheres, sem distinção, crianças e } \\
\text { adolescentes }\end{array}$ \\
\hline Concorrentes: não existem & $\begin{array}{l}\text { Fornecedores: material de expediente de uso diário e, em alguns casos, o Governo do Estado da Paraíba apoia } \\
\text { por meio de recursos financeiros. }\end{array}$ \\
\hline Complementadores: ONG Bamidelê & $\begin{array}{l}\text { Complementadores: sindicato dos professores, outras } \\
\text { ONGs e escolas }\end{array}$ \\
\hline
\end{tabular}

Fonte: Dados da pesquisa, 2016.

A rede de valores é composta por público-alvo, fornecedores, concorrentes e complementadores, o Quadro 2 apresenta as redes de cada ONG a partir da interpretação das percepções das dirigentes.

Nota-se que existem semelhanças nas redes de valor estabelecidas, no entanto, percebe-se que ao questionar quanto à possível existência dos concorrentes, a Dirigente A afirmou: "Não temos. A gente quer é agregar". Em contrapartida, a Dirigente B, apesar de confirmar a não existência de concorrência, explicitou que disputas são comuns ainda que outras ONGs atuem no mesmo setor. Nesse momento a fala da entrevistada foi:

Disputas entre as próprias entidades que atuam naquela área de mulheres existem [...] Quando é pra enfrentar o problema estamos juntas, mas não podemos negar as disputas [...] No sufoco se abraça, mas no dia a dia fica aquela coisa de menina adolescente querendo tomar o namorado da outra.

Ainda sobre a discussão quanto à ausência de concorrência, mas existência de disputa, a Dirigente B explicou:

Apesar de lutarmos pela mesma coisa, eu acho que tem muito a ver com a origem. Por exemplo, a gente da 8 de Março, a gente veio de sindicato, de rua, de fazer zoada, de mobilização, então eu acho que até hoje a gente traz essa cara [...] A nossa questão política é muito forte. Em nossa farda tem paixão, prazer e política. Se você pegar uma outra instituição que vem da universidade ou de outras origens, já vão ter um outro foco, um outro olhar.

Segundo Nalebuff e Brandenburger (1996), as organizações são complementadoras ao criarem mercados e concorrentes na divisão deles. Portanto, conforme afirma Pinheiro (2003) as ONGs têm se estabelecido como concorrentes umas das outras, tendo em vista que, embora não apresentem fins lucrativos para a execução de suas atividades e projetos, faz-se necessária a busca de capital, garantindo assim sua subsistência. Corroborando, Caldana, Barcelos e Camiloto (2012) afirmam que, mediante a expansão do terceiro setor, bem como o estabelecimento de alianças estratégicas com o Estado e mercado, o surgimento de concorrência entre as ONGs torna-se natural e inevitável, pois cada entidade busca mostrar-se 
competitiva para a obtenção de financiamentos dos seus projetos.

Ávila (1999), Cruz e Estraviz (2000), Corrullón e Medeiros Filho (2002), Tenório (1997) e Camargo, Suzuki, Ueda, Sakima e Ghobril (2001) reforçam essa percepção ao destacar que a captação de recursos entre ONG é elemento determinante para a sustentabilidade delas na rede de valores.

Observa-se então que, embora a Cunhã Coletivo Feminista e o Centro da Mulher 8 de Março não tenham se autoindicado como complementadoras, segundo a teoria descrita, as referidas ONGs o são, pois complementaridade surge quando ambas criam um mercado de atuação na luta e defesa dos direitos das mulheres, e concorrência quando dividem este mercado no que se refere aos recursos do Governo do Estado da Paraíba. Desse modo, entende-se que o Estado é um jogador que não se pode evitar, pois de uma maneira ou de outra, as organizações, sejam do segundo ou terceiro setor, criam laços de dependência com ele.

A seguir, demonstram-se questionamentos e respostas das dirigentes que se basearam em três principais abordagens: relação das ONGs com o Estado; impacto dessa relação para o público-alvo; e equilíbrio do poder de decisão mediante a relação com o Estado. Busca-se, portanto, fazer uma análise geral da relação das ONGs com o Estado.

Assim, obtiveram-se as seguintes afirmações:

\begin{abstract}
De parceria mesmo, porque é o estado democrático né? [...] A gente trabalha de uma maneira muito harmoniosa com o atual Estado. A gente sempre participa de todas as dificuldades. Lógico que temos nossas diferenças [...]. A gente nunca deixou de ser controle social, mas o controle social com uma gestão democrática tem muita diferença do que gestões passadas (Dirigente A).
\end{abstract}

Hoje nós temos uma boa relação com o Estado, até porque nós somos parceiros [...]. Por exemplo, a maioria das novas reivindicações nesses últimos anos foram atendidas, vamos dizer, de 2010 pra cá (Dirigente B).

Conforme descrito anteriormente, as ONGs em estudo têm suas origens na década de 1990, momento marcado por mudanças nas configurações sociais devido à reforma do Estado e a reformulação do marco legal do terceiro setor (Bresser-Pereira \& Grau, 1999; Fernandes, 1994; Sucupira et al., 2007). Portanto, assim como relatam Sucupira et. al. (2007), este período apresentou implicações no que tange a relações entre ONG e Estado, tendo em vista que houve ampliação do espaço público aos novos atores sociais, que resultou em maior participação social, consolidação e aprofundamento da democracia.

Em um esforço de descrever as relações entre ONG e Estado, Hulme e Edwards (1997) assumem que esse relacionamento é constituído entre parceiros relutantes, destacando que as relações, além de complexas, variam muito. Em contrapartida, em estudo realizado por 
Serva (1996) em uma produtora de artes, foi identificada a articulação em rede por meio de parcerias com outras organizações e o Estado.

A partir dos relatos das dirigentes, observou-se que, embora as ONGs em questão tenham surgido em regimes políticos diferentes em relação ao período atual desta pesquisa, e que, mesmo diante de modificações neste cenário, as instituições conseguiram desenvolver relação harmoniosa com o Estado ao longo do tempo, tendo seus papéis e atribuições bem definidos. Observou-se ainda que as dirigentes estabelecem um marco temporal específico para a melhora da relação com o Estado, atribuindo ao governo do Partido dos Trabalhadores (PT) (que ocorreu de 2003 a 2016) os avanços obtidos nas lutas dos direitos da mulher, bem como no relacionamento das entidades da sociedade civil com o setor estatal.

Ambas reconhecem que, por meio de um governo democrático, é possível construir melhores ações para a sociedade. Logo, assume-se que este resultado é semelhante ao encontrado no estudo feito por Sucupira et al. (2007), no qual os pesquisados reconhecem que tanto a função do Estado quanto o papel da sociedade civil têm se transformado ao longo dos anos.

Em seguida, foi indagado às entrevistadas suas percepções quanto aos impactos da relação de colaboração entre ONG e Estado no contexto social, bem como com seu públicoalvo, de modo que ambas afirmam que os resultados são positivos, agregando diversas conquistas, conforme apresentam as falas a seguir:

São resultados bastante eficazes por causa do diálogo com o Estado [...]. Não é à toa estão aí as delegacias das mulheres. Tem vários projetos que a gente construiu no diálogo (Dirigente A).

Em 2010 nós tínhamos quatro delegacias, hoje nós temos nove [...]. Criação dos centros de referências e ampliação desses centros para os interiores [...]. A criação do juizado de violência doméstica familiar contra a mulher foi uma das nossas maiores vitórias (Dirigente B).

Nota-se relação de interdependência entre ONG e Estado (Lecy \& Slyke, 2012; Pinheiro, 2003; Salamon \& Anheier, 1998; Young, 2000), em que cooperação e parceria devem ser o cerne entre a relação mencionada. Entendemos que esses setores não necessitam se substituir, mas complementar-se; afinal, as funções reguladoras do Estado não impossibilitam a participação das entidades não governamentais na sociedade de maneira efetiva.

Ao serem questionadas sobre como equilibrar poder de decisão e comando entre ONG e Estado, considerando que ambas as entidades são de naturezas diferentes, as dirigentes se pronunciaram:

A parceria com o Estado possui autonomia, agora, quando é uma parceria com convênio mesmo, a 
gente apresenta o projeto, então o Estado sabe exatamente como é a parceria, qual é as linhas que a gente atua [...]. A gente faz pressão para que o Estado cumpra com seu papel (Dirigente A).

O Centro 8 de Março é altamente independente de partidos, ele é autônomo, apesar do apoio, pois entendemos que é uma obrigação [...]. Não aceitamos nenhuma interferência de políticos e governantes (Dirigente B).

Segundo Ckagnazaroff, Costa e Souza (2010), as relações entre ONG, Estado e doadores assumem diversos papéis, dentre eles a negociação. Nesse sentido, verificou-se a existência de negociações entre entidades e Estado, diante das cobranças reivindicadas por parte das ONG - Dirigente A.

A partir dos relatos é possível analisar uma relação de parceria, cujos papéis de ONG e Estado são bem definidos, prezando-se assim pela independência decisória das entidades. Portanto, confirma-se a existência da "coopetição" na relação ONG-Estado, pois de um lado as entidades prezam pela manutenção de suas bandeiras de luta, que muitas vezes são conflituosas com pautas estatais, e, de outro, são aliadas na implementação de políticas sociais que geram impacto ao público-alvo atendido, preservando assim independência e autonomia na atuação.

\subsection{Identificando as PARTS}

\subsubsection{Jogadores}

Na perspectiva das PARTS, jogadores são todos que compõem a rede de valores. Nesse sentido foi questionado às dirigentes como acontecem relações dentro da rede de valores das ONGs as quais envolve público-alvo (público atendido ou comunidade atendida), fornecedores, concorrentes e complementadores.

Ao serem indagadas quanto à existência de concorrentes para as ONGs, ambas as entrevistadas afirmaram a não existência de concorrência entre as entidades. Entretanto, a Dirigente B expressa em seu discurso que são comuns disputas entre ONG do mesmo setor em busca de recursos.

Apesar de não assumirem claramente a existência da complementaridade entre jogadores, entende-se que a partir da criação de um mercado de atuação (luta pelos direitos das mulheres) essa interação complementar concretiza-se. Para Nalebuff e Brandenburger (1996) a interatividade do jogo nas organizações indica que os papéis são alteráveis, sendo um jogador concorrente hoje, pode ser complementador amanhã. Ainda, Caldana, Barcelos e 
Camiloto (2012) explicitam a complementaridade das ONG a partir da concorrência estabelecida entre as mesmas, uma vez que a disputa por alianças estratégicas com o Estado para financiamentos de projetos se faz uma realidade no terceiro setor.

Para continuar a identificação dos jogadores da rede de valor sentiu-se a necessidade de questionar se algum membro da ONG faz parte da estrutura governamental:

\begin{abstract}
Atualmente a equipe que tá, tá muito aqui. Uma coisa que a gente sempre achou que era complicado, foi por exemplo, eu, tá aqui e tá na Secretaria [de Estado da Mulher e da Diversidade Humana]. Por isso a gente entrou com um acordo com o Conselho Consultivo e com o Conselho Fiscal, um acordo não, mas fica muito contraditório, como é que eu vou dialogar com o Estado, reivindicar uma coisa, se eu também estou cá e lá? Eu acho que parceria deve existir, mas o diálogo não deve ser confundido. Eu tô no lugar de movimento social, quem tá no Governo, tá no Governo, vai dialogar lá com o Governo, com o Governador para reivindicar. Mas aqui já se trabalhou pessoas em outras secretarias que não sejam tão diretas da causa que a gente defende (Dirigente A).
\end{abstract}

Não, mas quem foi se afastou. Uma outra coordenadora, ela foi para o governo, para o Cendac [Centro de Apoio às Crianças e aos Adolescentes], mas ela se afastou do Centro da Mulher 8 de Março (Dirigente B).

Segundo Nalebuff e Brandenburger (1996), toda vez que um jogador joga dois jogos, ambos são potencialmente ligados e a existência desse jogador em comum na rede de valores determina a possibilidade de elo entre os jogos. No entanto, verificou-se que as ONGs deste estudo, apesar de manterem ligação com o Estado por meio de parcerias, não possuem pessoas (jogadores) que fazem parte simultaneamente dos dois setores (Terceiro Setor e Estado).

Nesse sentido, torna-se relevante destacar que, conforme Ckagnazaroff, Sátiro e Gontijo (2007), a parceria entre ONG e Estado propicia vantagens na complementação das atividades executadas por ambas as partes, mas que a depender do nível de interação também pode tornar-se nociva caso afete cobrança, capacidade crítica e controle da entidade. Portanto, de acordo com as falas descritas, há ex-dirigentes e fundadoras das entidades que atualmente fazem parte do governo da Paraíba, mas que não apresentam mais vínculo com a organização, garantindo assim a lisura na independência na relação com o Estado, pois, tendo em vista que primeiro e terceiro setor possuem naturezas distintas, acredita-se que a vinculação de um mesmo jogador em ambos poderia resultar em divergências significantes de interesses, a ponto de colocar em risco a autonomia das ONGs diante do Estado. 


\subsubsection{Valores adicionais}

Ao tratar de valores nas organizações do terceiro setor é comum relacioná-los a solidariedade e reciprocidade. Para Serva (1996), pelos valores contidos na base das ONG, acredita-se que a racionalidade substantiva é predominante, porém inserida na sociedade atual e centrada no mercado, em que regras são estabelecidas e orientadas a partir de relações mercantis (Ramos, 1981). Nesse jogo são avaliados os valores adicionais de cada jogador em suas jogadas (Nalebuff \& Brandenburger, 1996). Neste artigo o "jogo" analisado se refere à relação que as ONGs estabelecem entre si e com o Estado.

Desse modo, as dirigentes foram questionadas sobre valores adicionais. Para Cunhã Coletivo Feminista, valores adicionais são baseados: "na participação em uma instância nacional de representação dos direitos das mulheres, a Articulação de Mulheres Brasileiras (AMB) e principalmente no histórico de lutas da entidade, que inspira credibilidade". Enquanto, para o CM8M, tem-se como valor adicional: "nosso histórico de lutas de rua, onde sempre a questão política foi um dos nossos principais diferenciais, afinal, o político deve estar em todas as nossas ações. Não é o partido político, mas é a questão política".

Quando as dirigentes afirmam que pautas de lutas em defesa de direitos são valores adicionais, se contrapõem com as constatações de Reis (2001) de que o processo de institucionalização dos movimentos sociais para as ONGs colocou em risco suas pautas históricas e trouxe contradições em relação ao papel que tais organizações se propõem a desempenhar. Nesse sentido, evidenciar valores adicionais é importante para manter conformidade entre os objetivos declarados e executados, evitando que incorram no risco de falácias como aconteceu em algumas ONG pesquisadas por Lacerda (2010).

Ainda na discussão desta categoria, foi questionado às dirigentes se em um cenário hipotético em que as ONGs não existissem, se elas acreditariam na permanência das lutas pelas quais militam enquanto entidade, uma vez que, segundo a Teoria da Coopetição, as organizações buscam monopolizar, ou seja, deter valores adicionais que lhes são únicos, diferenciando-se das demais organizações. Verificou-se, portanto, percepções diferentes das entrevistadas, conforme seguem as falas: "Muito difícil falar o 'se' [...]. Não sei”" (Dirigente A); e "Não, de jeito nenhum. Nós sabemos que o Centro da Mulher 8 de Março tem um impacto muito grande na sociedade paraibana [...]. Nos últimos quatro anos nós atendemos um número de cinco mil crianças e adolescentes dentro das escolas, esse trabalho ninguém na Paraíba se propôs a fazer como o Centro da Mulher faz” (Dirigente B). 
Diante das falas pode-se dizer que, para a primeira, o cenário não se configura como monopólio. A partir de Nalebuff e Brandenburger (1996) isso pode significar que sem determinado jogador não há jogo, sendo o valor adicional correspondente ao bolo inteiro posição indiscutivelmente invejável. Em contrapartida, para a Dirigente B, a ONG que coordena possui valores adicionais monopolizados, como bem destacou ao citar ações em escolas do estado afirmando que: "esse trabalho ninguém na Paraíba se propôs a fazer como o Centro da Mulher faz" (Dirigente B).

Em seguida, ainda sobre questionamentos em relação aos valores adicionais, as dirigentes falaram sobre o fato de terem projetos e ações copiadas por outras organizações:

Trabalhamos com uma metodologia que atrai, a questão da educação [da] população [...] nós já recebemos prêmios de reconhecimento da metodologia que foi replicada por nós e por outras pessoas [...] recebemos muito feedback, ah, a gente fez muita coisa igual a metodologia de vocês (Dirigente A).

isso acontece sempre, inclusive a gente incentiva, quando a gente realiza uma atividade a gente incentiva, o nosso objetivo é criar multiplicadores, entende? é multiplicar a nossa ideia, então várias e várias vezes já aconteceu (Dirigente B).

Os relatos apontam para o que Nalebuff e Brandenburger (1996) denominam de “imitação saudável”, tendo em vista que ambas se mostraram solícitas a essas atitudes ao afirmar que o objetivo é multiplicar ações, pois compreendem que as consequências de ter seus comportamentos copiados por outras entidades produzem impactos positivos na sociedade. Corroborando com o achado desta pesquisa, classificamos as ONGs estudadas como colaborativas neste quesito, pois quando percebem criação ou adição de valores comuns, conectividade de objetivos e parcelas semelhantes de responsabilidades estão submetidas a um acordo entre partes, conceito básico para a cooperação (Sousa \& Valadão Júnior, 2010).

Caso as ONGs estudadas se orientassem na perspectiva da competição, considerando uma visão meramente gerencialista, não aceitariam as imitações saudáveis. Para Martins (1994), em ambientes em que valores governantes são os da competição "cada um cuida de ganhar e fazer o outro perder" (Martins, 1994, p. 70). Esse fato foi constatado por Oliveira (2013) ao se fundamentar na visão baseada em recursos pesquisando a trajetória da ONG Parceiros Voluntários. 


\subsubsection{Regras}

As entrevistadas foram questionadas sobre quais regras são mantidas na relação ONGEstado. A Dirigente A mencionou: "Eu acho que as regras são mais ocultas, né? [...] Tem regras assim, ó, eu sou sociedade civil, e você é o Estado, vamos dialogar. Não tem regras assim, ó, eu faço isso e você faz aquilo [...]. A gente sabe”. Já a Dirigente B afirmou que: "Temos uma boa relação, desde de que não haja interferência [...]. O que existe entre nós e o Estado é o respeito a ONG, respeito a entendida, sabe? É o respeito mútuo".

Percebe-se pelas falas que as regras estabelecidas estão baseadas em aspectos subjetivos, que não estão previstos em documentos, mas construídos ao longo do tempo, como o senso da responsabilidade de cada um e o respeito. Essa subjetividade é considerada como jogo organizacional "implícito" (Nalebuff \& Brandenburger, 1996), tendo em vista que as regras não estão declaradas.

Mesmo identificando que não existem regras formais para regulamentar a relação ONG-Estado, as entrevistadas destacaram alguns procedimentos necessários para a obtenção de recursos do Estado, como exemplo: contratos, editais e processos licitatórios. Nesse momento ficou evidenciado o conflito entre as racionalidades substantiva e instrumental na concretização das ações, pois algumas situações exigem que as ONGs se posicionem de maneira instrumental, assumindo elementos baseados na ordem burocrática e impessoal, em detrimento à substantividade característica comum ao terceiro setor (Lacerda, 2010). Essas percepções podem ser confirmadas por meio das falas:

\footnotetext{
A burocracia, aff! A burocracia ela impede, complica, complexifica muito, porque por exemplo temos um edital aí, do Governo Federal por exemplo, mas a burocracia é tão grande que às vezes a gente não consegue [...] Sistemas que não permite que as ONG acessem com facilidade [...] (Dirigente A).

Nós temos a questão da licitação [...]. Nós não trabalhamos diretamente com aquela licitação que o Estado faz não, que é bem complicada. Mas nós trabalhamos com o tipo de, por exemplo: qualquer coisa que nós formos comprar pra o projeto, nós temos que fazer três tipos de orçamentos [...]. Nós temos que pedir três orçamentos de empresas diferentes [...]. Mas isso não traz problema pra gente não, sabe? Isso é uma coisa que a gente trabalha muito bem (Dirigente B).
}

A partir das falas, observa-se que a Dirigente A apresenta nível de conflito com as regras explícitas entre ONG e Estado no que tange aos processos burocráticos, considerando que suas críticas são fundamentadas nas disfunções burocráticas apresentadas pelo setor público. Percebe-se, por outro lado, certo conformismo no relato da Dirigente B, quando diz não ter problemas, assumindo que essa é uma realidade à qual as organizações devem se submeter ao optarem pela relação com o Estado. 
As falas das dirigentes estão em acordo com alguns aspectos evidenciados por Almeida (2011) em pesquisa que avaliou a relação entre mercado, estado e terceiro setor. O autor alega que o Estado é um excelente parceiro na governação, mas, por outro lado, é o mesmo que organiza as condições dela, cabendo-lhe a definição dos dispositivos reguladores, o que pode ser um problema na relação com outros atores sociais, como as ONGs. Porém as organizações do terceiro setor (OTS) estudadas por Almeida (2011) em Portugal, constroem junto com o Estado o quadro regulador, consequência de uma boa relação, apesar das características heterogêneas entre os setores.

\subsubsection{Tática}

Segundo Nalebuff e Brandenburger (1996), assim como valores adicionais e regras são elementos importantes em um jogo, as percepções dos jogadores também compreendem um fator fundamental, pois os autores afirmam que a maneira pela qual indivíduos percebem o jogo irá influenciar suas jogadas. Corroborando, Ckagnazaroff, Costa e Souza (2010) afirmam que o sucesso ou fracasso de uma ONG depende de sua habilidade de influenciar o ambiente e avaliar os fatores do ambiente externo, muito importantes para seus programas e atividades.

Desse modo, esses aspectos foram analisados por meio do questionamento referente a quais percepções as ONGs gostariam de preservar entre si e o Estado. Para a Dirigente A, trata-se de: "Tem de ter clareza do papel de cada um. Tem que ter tranquilidade quando a gente tá fazendo o movimento [...]. Tem que ter tranquilidade de fazer parceria onde é possível se fazer. Onde é possível preservar esses espaços”. Já a Dirigente B menciona: “O respeito, a parceria".

Ainda dentre as táticas dos jogos, indagou-se sobre o que as dirigentes mudariam no que tange às relações com o Estado. A primeira destacou: "a mudança nos entraves burocráticos" e a segunda, embora em um primeiro momento tenha afirmado que não teria o que mudar, em seguida retificou dizendo: "Mais apoio. Acho que é por aí, mais apoio do Estado para as entidades".

Partindo da premissa de que a tática entre determinada rede de valor consiste no poder que se tem de moldar as percepções dos envolvidos (Luke, 1999; Nalebuff \& Brandenburger, 1996), a partir das falas destacadas, observou-se que a Dirigente A apontou como tática a tranquilidade e preservação das relações de parceria, enquanto a B destacou a relação de respeito e também parceria. Portanto, confirma-se a boa relação de colaboração estabelecida 
entre as ONGs em questão e o Estado, assim como foi descrito anteriormente. No entanto, quanto aos aspectos que as dirigentes mudariam nessa relação, constatou-se que dentre as táticas presentes no jogo também há elementos que não contribuem com a cooperação entre eles, tais como: burocracias e possível ausência de apoio nas atividades, podendo assim interferir na parceria estabelecida.

Seguindo a proposta do escopo, Pinheiro (2003) afirma que o problema do terceiro setor é ainda não ter consciência de sua condição. Há por parte dele a ausência de identidade, que causa falta de poder. Como não existe poder, o terceiro setor não tem como tratar de forma igual mercado e Estado; sendo assim, não há como lidar com as adversidades que a sociedade civil passa em seus respectivos países.

\subsubsection{Escopo}

O escopo compreende os limites que as pessoas, ainda que de maneira implícitas, atribuem aos jogos (Nalebuff \& Brandenburger, 1996). Aliado a essa perspectiva, têm-se o estudo de Serva (1997) em que são apresentados três cenários de parcerias entre Estado e ONG. No primeiro cenário apresenta-se uma parceria pontual, no segundo, uma parceria ampliada, mas ainda dirigida pelo Estado e no terceiro cenário há parceria ampliada com mutação cultural, em que os atores sociais constroem efetivamente as ações sociais coletivamente com o Estado.

Para a análise do escopo das ONGs, metodologicamente optou-se por não delimitar questionamentos específicos sobre essa temática, entendendo que tais limites estariam intrinsecamente presentes nas falas das dirigentes ao dissertar sobre a relação ONG-Estado.

Nesse contexto, percebeu-se que o escopo entre o jogo da relação entre as ONGs com o Estado apresenta como limites a parceria, porém sem sacrificar autonomia, independência, respeito mútuo, definições do papel e responsabilidades de cada setor, predominando assim uma transição entre o segundo e terceiro cenários descritos por Serva (1997), que demonstra a construção de uma relação coopetitiva com o Estado.

Tais resultados podem ser relacionados com os estudos de Ckagnazaroff, Sátiro e Gontijo (2007), nos quais os autores concluem a pesquisa com o entendimento de que as parcerias estabelecidas entre ONG e Estado são uma estratégia eficaz para solucionar problemas que nenhum dos lados teria condições de resolver sozinho. O estudo também reconhece que existem problemas nessas parcerias, principalmente por se tratarem de práticas 
novas as relações entre as ONGs e o Estado, que, de acordo com a pesquisa de Bava (2015), sempre foram delicadas: para que as parcerias sejam consolidadas e os limites que uma cultura autoritária constrói sejam superados, faz-se necessário que o Estado respeite a autonomia das ONGs e ao mesmo tempo se preocupe em fortalecê-las.

\subsection{Influência da criação da Secretaria de Estado da Mulher e da Diversidade Humana (SEMDH) na relação ONG-Estado}

Entre as discussões sobre relações entre Estado e terceiro setor, Gohn (2004) destaca os movimentos sociais - principalmente das mulheres, da igreja cristã e das ONGs - como responsáveis por disseminar a importância da participação social incentivando novas práticas institucionalizadas. Na opinião de Doimo (1995, p. 223), "cada vez mais fala-se menos em 'democracia de base' e mais em 'democracia como valor universal', menos em 'movimento popular' e mais em 'movimentos sociais organizados', menos em 'luta contra o Estado' e mais em "participação da sociedade nas decisões"”.

Partindo desse pressuposto, nesta seção objetiva-se descrever as percepções das dirigentes quanto à influência da criação da SEMDH na relação entre as ONGs e o Estado.

Segue, portanto, o destaque das principais falas em questão:

Pra coordenadoria sempre foi uma luta. Então é importantíssimo ter essa interlocução [...]. É importantíssimo ter essa Secretaria da Mulher e da Diversidade Humana. É tanto que a gente sempre lutou pra ser uma específica né? Não foi, mas tá aí com a secretaria que vem dos movimentos sociais, que facilita muito também o diálogo (Dirigente A).

Foi a maior conquista do movimento de mulheres! [...] Porque primeiro, elas fazem com que as políticas públicas aconteçam [...]. O movimento cobra da secretaria e a secretaria cobra do governo [...]. Essas secretarias são mediadoras. E houve um grande avanço na Paraíba após a criação da Secretaria de Mulher e Diversidade Humana. Podemos dizer que o Estado nunca teve um avanço tão grande depois da criação delas (Dirigente B).

As falas das entrevistadas expressam o momento vivido pelas ONGs de 1990 até a atualidade, que a partir de uma perspectiva democrática vive diferentes relações com o poder público, entre elas, reivindicações empreitadas buscando e consolidando seu compromisso histórico com o aprofundamento da democracia (Dagnino \& Padula, 2002; Jaime, 2005; Oliveira, 2002; Teixeira, 2003).

Assim a influência da criação da SEMDH na relação ONG-Estado deu-se de maneira efetiva e positiva, sendo a maior conquista das ONGs militantes pelos direitos das mulheres, 
além de que se verificaram impactos satisfatórios nos demais elementos (PARTS) do jogo, analisados anteriormente. A existência da SEMDH, atuando como mediadora das ONGs com o Estado, melhora comunicações entre jogadores constituintes da rede de valor, gerando valor adicional para as entidades, bem como facilitando as regras estabelecidas, as táticas e o escopo.

\section{Considerações Finais}

As ONGs estudadas possuem posições ideológicas semelhantes, conforme se observa nas entrevistas analisadas no que tange ao setor de atuação, público-alvo e o próprio surgimento, com trajetória de militância na luta dos direitos das mulheres na Paraíba. Apesar dessa constatação é importante reforçar que suas raízes se distinguem no sentido de uma organização ser oriunda de movimentos sindicais e outra dos universitários. Esses aspectos levam-nos à afirmação da dinamicidade da sociedade civil organizada e, por consequência, suas relações com outros setores, dentre eles o Estado, escolhido no estudo como elo de avaliação com as ONGs.

Do que foi analisado, conforme os resultados apresentados nesta pesquisa e em resposta aos objetivos do estudo, é possível inferir que as alianças intersetoriais (parcerias) proporcionam o fortalecimento entre as ONGs e com o Estado, tratando-se de um relacionamento em rede. Porém destaca-se que os elementos de competição devem ser preservados, dada a natureza delas e de suas lutas, voltadas para as características do ativismo social, oriundo de suas histórias. Para tanto, aliar esses dois movimentos (cooperação e competição) é assumir um modelo baseado na coopetição, no qual se estabelece como componente estratégico, podendo-se propor políticas públicas baseadas no princípio do ganha-ganha entre Estado, terceiro setor, e, por conseguinte, sociedade, que é beneficiada com contribuições efetivas de impacto social. Assim, pode-se assumir que, por ora, há mais uma postura de convergência de interesses do que de afastamento.

Apesar de o modelo de coopetição, baseado nos autores Nalebuff e Brandenburger (1996), ser amplamente difundido nessa pesquisa, reconhece-se como limitação o fato de os autores terem cunho mercadológico, encontrando-se na literatura científica poucos estudos que analisem coopetição por suas lentes. $\mathrm{Na}$ introdução do próprio livro os autores reconhecem que esse modelo é fornecido para aplicabilidade empresarial. No que se refere ao terceiro setor, esta pesquisa destaca-se pelo ineditismo no uso do modelo da forma como os 
autores propõem.

Em estudos futuros faz-se necessário também avaliar a perspectiva do Estado no que tange à rede de valores, e qual o lugar que as ONGs ocupam nela. Desse modo, outras percepções podem ser analisadas, bem como estratégias baseadas nas táticas de cada setor. Afinal, como visto no decorrer deste artigo, as percepções variam de jogador a jogador.

\section{Referências}

Almeida, V. (2011). Estado, mercado e terceiro setor: a redefinição das regras do jogo. Revista Crítica de Ciências Sociais, (95), 85-104.

Anheier, H. K. (2005). Nonprofit organizations: theory. management, policy. London: Routledge.

Austin, J. E. (2001). Parcerias: fundamentos e benefícios para o terceiro setor. São Paulo: Futura.

Ávila, C. M. (Coord.) (1999). Gestão de projetos sociais (2a ed.). São Paulo: Associação de Apoio ao Programa Capacitação Solidária.

Azevedo, G., Carvalho, H. F., \& Silva, J. F. (1999). A teoria dos jogos na estratégia de negócios: uma contribuição relevante? In Iberoamerican Academy of Management International Conference, 1. Madri: Iberoamerican Academy of Management.

Bava, S. C. (2015). As ONGs e as políticas públicas na construção do estado democrático. Revista do Serviço Público, 45(3), 97-100.

Berger, P. L., \& Luckmann, T. (2003). A construção social da realidade. Petrópolis, RJ: Vozes.

Bresser-Pereira, L. C., \& Grau, N. C. (Orgs.). (1999). O público não estatal na reforma do Estado. Rio de Janeiro: Fundação Getúlio Vargas.

Caldana, A. C. F., Barcelos, L. S., \& Camiloto, C. M. (2012). Sentidos das ações voluntárias: desafios e limites para a organização do trabalho. Psicologia \& Sociedade, 24(1), 170177.

R.G. Secr., GESEC, São Paulo, v. 9, n. 1, p 236-264, jan./abr. 2018. 
Calegare, M. G. A., \& Silva Júnior, N. (2009). A “construção" do terceiro setor no Brasil: da questão social à organizacional. Revista Psicologia Política, 9(17), 129-148.

Camargo, M. F., Suzuki, F. M., Ueda, M., Sakima, R. Y., \& Ghobril, A. N. (2001). Gestão do terceiro setor no Brasil. São Paulo: Futura.

Cândido, G. A, \& Abreu, A. F. (2000). Os conceitos de redes e as relações interorganizacionais: um estudo exploratório. In Encontro da Anpad, 24. Rio de Janeiro: Anpad.

Ckagnazaroff, I. B., Costa, M. T. G., \& Souza. (2010). Relação entre ONG e o Estado: um estudo de parceria. Revista Gestão \& Tecnologia, 2(1). Recuperado em 6 dezembro, 2017, de https://goo.g1/L3nLdK

., Sátiro, V. L., \& Gontijo, P. H. G. (2007). ONGs e Estado: duas percepções de parcerias. (2007). In Conferência Regional de ISTR para América Latina y el Caribe, 6. Salvador: ISTR.

Coelho, S. C. T. (2000). Terceiro setor: um estudo comparado entre Brasil e Estados Unidos. São Paulo: Senac.

Cruz, C. M., \& Estraviz, M. (2000). Captação de diferentes recursos para organizações sem fins lucrativos. São Paulo: Global.

Dagnino, G. B., \& Padula, G. (2002). Coopetition strategy: a new kind of interfirm dynamics for value creation. Trabalho apresentado em The European Academy of Management Second Annual Conference. Recuperado em 6 dezembro, 2017, de https://goo.gl/oC5BCa

Doimo, A. M. (1995). A vez e a voz popular: movimentos sociais e participação política no Brasil pós-70. Rio de Janeiro: Relume-Dumará/Anpocs.

Dowbor, L. (2002). Parcerias e alianças: o bom senso na gestão social: uma abordagem conceitual das políticas para crianças e adolescentes. São Paulo: Blog do Professor Ladislau Dowbor. Recuperado em 6 dezembro, 2017, de https://goo.gl/u2q1Tw

Eiriz, V. Proposta de tipologia sobre alianças estratégicas. (2001). Revista de Administração 
Contemporânea, 5(2), 65-90.

Eikebrokk, T. R., \& Olsen, D. H. (2005). Co-opetition and e-business success in SMEs: an empirical investigation of European SMEs. In 38 Annual Hawaii International. Conference on System Sciences. Big Island, HI: IEEE.

Fernandes, R. C. (1994). Privado porém público: o terceiro setor na América Latina. Rio de Janeiro: Relume-Dumará.

Fischer, R. M. (2005). Estado, mercado e terceiro setor: uma análise conceitual das parcerias intersetoriais. Revista de Administração, 40(1), 5-18.

Geertz, C. (1989). A interpretação das culturas. Rio de Janeiro: LTC.

Gohn, M. G. (2004, 2 de abril). Movimentos sociais: espaços de educação não formal da sociedade civil. Universia. Recuperado em 6 dezembro, 2017, de https://goo.gl/ubyofb

Hulme, D., \& Edwards, M. (1997). NGOs, States and donors: an overview. In Banks, N., Hulme, D., \& Edwards, M. (Eds.), ONG's, states and donors: too close for comfort? (pp. 9-22). London: Macmillan Press.

Jaime, P. (2005). Da construção à crise de identidade das ONGs: notas para uma pesquisa etnográfica. In Congresso Brasileiro de Sociologia, 12. Porto Alegre: Sociedade Brasileira de Psicologia.

Lacerda, D. S. (2010). Organizações não governamentais (ONGs) e mercado: estudo de campo de um inevitável choque de racionalidades. Dissertação de mestrado em Gestão Empresarial, Fundação Getúlio Vargas, Rio de Janeiro.

Lecy, J. D., \& Slyke, D. M. V. (2012). Nonprofit sector growth and density: testing theories of government support. Journal of Public Administration Research and Theory, 23(1), 189-214.

Luke, T. W. (1999). Environmentality as green governmentality. Discourses of the Environment, 121-151.

Machado-da-Silva, C. L., \& Coser, C. (2006). Rede de relações interorganizacionais no campo organizacional de Videira - SC. Revista de Administração Contemporânea, 10(4), 
9-45. Recuperado em 8 dezembro, 2017, de https://goo.gl/uWw5tV

Martins, W. N. F. (1994). Mudança organizacional e ação comunicativa: rumo ao resgate da dignidade e da emancipação humana. Tese de doutorado em Administração, Fundação Getúlio Vargas, São Paulo.

Motta, F. C. P., \& Vasconcelos, I. F. G. (2006). Teoria geral da administração. São Paulo: Pioneira Thomson Learning.

Nalebuff, B. J., \& Brandenburger, A. (1996). Coopetição: 1. um conceito revolucionário que combina competição com cooperação, 2. a estratégia da Teoria do Jogo que está mudando o jogo dos negócios. São Paulo: Rocco.

Oliveira, L. A. G. (2002). As alianças estratégicas e as pequenas e médias empresas: uma análise a partir de três estudos de caso no comércio varejista de Fortaleza. In Encontro da Associação Nacional dos Programas de Pós-graduação e Pesquisa em Administração, 26. Rio de Janeiro: Anpad.

Oliveira, T. R. (2013). Dependência e criação de trajetória no terceiro setor: um estudo de caso na ONG Parceiros Voluntários. Dissertação de mestrado em Administração, Universidade do Vale do Rio dos Sinos, São Leopoldo.

Oliver, C. (1990). Determinants of interorganizational relationships: integration and future directions. Academy of Management Review, 15(2), 241-265.

Pinheiro, D. (2003). Sustentabilidade social de uma organização da economia social: um estudo de caso na Afece - Associação Franciscana de Educação ao Cidadão Especial. Dissertação de mestrado em Administração, Universidade Federal do Paraná, Curitiba.

Ramos, A. G. (1981). A nova ciência das organizações: uma reconceituação da riqueza das nações. Rio de Janeiro: Fundação Getúlio Vargas.

Reis, L. G. C. (2001). A racionalidade substantiva na avaliação de projetos em ONGs: três casos. Dissertação de mestrado em Administração Pública, Fundação Getúlio Vargas, Rio de Janeiro.

Rifkin, J. (1997). Identidade e natureza do terceiro setor. In Ioschpe, E. $3^{\text {o }}$ Setor: 
desenvolvimento social sustentado (pp. 17-35). Rio de Janeiro: Paz e Terra.

Salamon, L. M., \& Anheier, H. K. (1998). Social origins of civil society: explaining the nonprofit sector cross-nationally. Voluntas: International Journal of Voluntary and Nonprofit Organizations, 9(3), 213-248.

Secretaria de Estado da Mulher e da Diversidade Humana. (n.d.). Mulher e diversidade humana: histórico. Recuperado em 8 de dezembro, 2017, de https://goo.gl/BJbRHh

Serva, M. (1996). Racionalidade e organizações: o fenômeno das organizações substantivas. Tese de doutorado, Fundação Getúlio Vargas, São Paulo.

(1997). O Estado e as ONGs: uma parceria complexa. Revista de Administração Pública, 31(6), 41-54.

Sousa, E., \& Valadão Júnior, V. M. (2010). Alianças estratégicas: articulações entre o terceiro setor e o governo. Gestão. Org: Revista Eletrônica de Gestão Organizacional, 8(2), 158172.

Souza, A. A. (2003). A teoria dos jogos e as ciências sociais. Dissertação de mestrado, Universidade Estadual Paulista, Faculdade de Filosofia e Ciências, São Paulo. Recuperado em 8 dezembro, 2017, de https://goo.gl/QZCMVN

Sucupira, L. A., Chaves, A. D., \& Monteiro, M. G. (2007). ONGs e Estado: entre a retórica e a prática. In Encontro da Associação Nacional de Pós-graduação e Pesquisa em Administração, 31. Rio de Janeiro: Anpad.

Teixeira, S. L. (2003). Estratégias de internacionalização: um modelo para as PME: aplicação à indústria portuguesa do calçado. Actas de las XIII Jornadas Hispano-Lusas de Gestión Científica, 1, 505-514.

Tenório, F. G. (1997). Gestão de ONGs: principais funções gerenciais. São Paulo: FGV.

Vieira, A. A. (2014). Perspectivas contemporâneas das políticas públicas para a consecução da igualdade de gênero. Trabalho de Conclusão de Curso, Universidade Estadual da Paraíba, Faculdade de Direito, Campina Grande, PB.

Weisbrod, B. (1977). The voluntary nonprofit sector. Lexington, MA: Lexington Books. 
Amorim, A. F. A., Mendes, J. S., Pereira, L. M. L., \& Cavalcante, C. E. (2018)

Weymer, A., \& Machado-da-Silva, C. L. (2006). Cooperação, competição e poder entre organizações do Porto de Rio Grande - RS. 2006. In Encontro da Associação Nacional de Pós-graduação e Pesquisa em Administração, 30. Rio de Janeiro: Anpad.

Young, D. R. (2000). Alternative models of government-nonprofit sector relations: theoretical and international perspectives. Nonprofit and Voluntary Sector Quarterly, 29(1), 149172. 